\title{
Sustainable Levels of Human Impact for Hector's Dolphin
}

\author{
E. Slooten* and S.M. Dawson
}

Departments of Zoology and Marine Science, University of Otago, Dunedin, New Zealand

\begin{abstract}
Hector's dolphin is endemic to New Zealand, and listed as endangered on the IUCN Red List and equivalent New Zealand list of threatened species. The main threat to the species is entanglement in fishing gear, in particular gillnets. The Potential Biological Removal (PBR) method developed by the US National Marine Fisheries Service is a commonly used standard for determining a level of bycatch for marine mammal populations which, if exceeded, is likely to cause population decline. For Hector's dolphin, PBRs are less than one individual per year for most populations and the total for the whole species is less than 10 per year. Current estimated bycatch is on the order of 10-35 times higher than these PBRs. This is consistent with several Population Viability Analyses indicating that under current management Hector's dolphin populations are declining rapidly.
\end{abstract}

\section{INTRODUCTION}

Hector's dolphin Cephalorhynchus hectori is endemic to New Zealand and is classified as Endangered [1]. The North Island population, recently designated a separate subspecies Cephalorhynchus hectori maui [2] is listed as Critically Endangered. Like many other coastal cetaceans [3] the most serious threat to the species is entanglement in fishing gear [4]. Hector's dolphin populations have been seriously depleted, to less than a third of original population size, with the North Island population worst affected at less than $10 \%$ of original size [5]. This decline started in the early 1970s with the introduction of monofilament gillnets and the consequent expansion of the gillnet fishery in New Zealand. Previous gillnetting, using nets made of cotton, hemp and other natural materials had been relatively small scale.

The New Zealand Government has recently released a draft Threat Management Plan (TMP) for the species [4]. Proposed protection measures include protected areas and changing to more selective fishing methods that do not catch dolphins. Three options were presented to the public for consideration. Option 1: Current management with minor changes in voluntary codes of practice and monitoring. Option 2: Closing inshore areas to gillnetting (out to 2 or 4 nautical miles offshore, depending on the area) and trawling (out to 2 nautical miles, with exceptions for some target species), either year-round or seasonally. This option comprises a mix of protection measures with some area closures, some seasonal, some areas left unprotected. It includes regulations and voluntary measures. Option 3: Protection from bycatch in gillnets for most of the range of the species, out to 6,12 or 18 nautical miles offshore (depending on the area) and restrictions on trawling (within 2 or 4 nautical miles, depending on the area). The draft plan discusses the concept of Potential Biological Removal (PBR) [6] as a guide to how much protection would be required to avoid further popula-

*Address correspondence to this author at the Departments of Zoology and Marine Science, University of Otago, Dunedin, New Zealand; Tel: 00643 47-7980; Fax: 00643 47-7584; E-mail: liz.slooten@otago.ac.nz tion declines. Here, we explain the method, discuss its application and calculate PBRs for Hector's dolphin populations.

\section{MATERIALS AND METHODOLOGY}

The PBR method [6] aims to ensure that human-caused mortality is below levels that could lead to population depletion. It is based on a logistic model of population growth (Fig. 1a) in which maximum net productivity level (MNPL) is at $0.5 \mathrm{~K}$ (Fig. 1b). In this model population growth rate will be zero at $\mathrm{K}$ and greatest at very small population sizes (Fig. 1c). MNPL is the population size that results in the maximum number of individuals being added to the population per year (births minus deaths; Fig. 1b). For marine mammals this level is thought to be between $0.5 \mathrm{~K}$ and 0.85 $\mathrm{K}$ (i.e. a skewed, theta-logistic distribution if $\mathrm{MNPL}>0.5$ ) [7].

The method explicitly takes into account uncertainty and potential biases in the available information. A PBR is calculated using using the following simple formula:

$\mathrm{PBR}=\mathrm{N}_{\min } \times 0.5 \mathrm{R}_{\max } \times \mathrm{F}_{\mathrm{r}}$

Where:

$\mathrm{N}_{\text {min }}=20^{\text {th }}$ percentile of the population size estimate

$\mathrm{R}_{\max }=$ Maximum annual population growth rate

$\mathrm{F}_{\mathrm{r}}=$ Recovery factor

In the design of the PBR method, a range of mortality limits were evaluated based on whether at least $95 \%$ of the simulated populations met two criteria: (1) populations starting at the maximum net productivity level (MNPL) stayed there or above after $20 \mathrm{yr}$, and (2) populations starting at 0.3 of carrying capacity $(\mathrm{K})$ recovered to at least MNPL after $100 \mathrm{yr}$ [6]. Simulations indicated that using the $20^{\text {th }}$ percentile of the population size estimate (lower $60 \%$ log-normal confidence limit) met those criteria for both cetaceans and pinnipeds [6]. $\mathrm{N}_{\min }$ estimates for Hector's dolphin populations came from a recent series of line-transect surveys [8$10]$.

At a population size $0.5 \mathrm{~K}$ one would expect the population growth rate to be approximately $0.5 \mathrm{R}_{\max }$ (Fig. 1c). As 
(a)

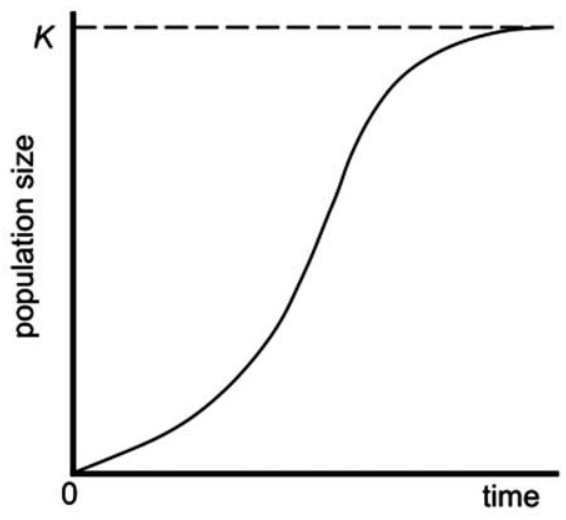

(b)

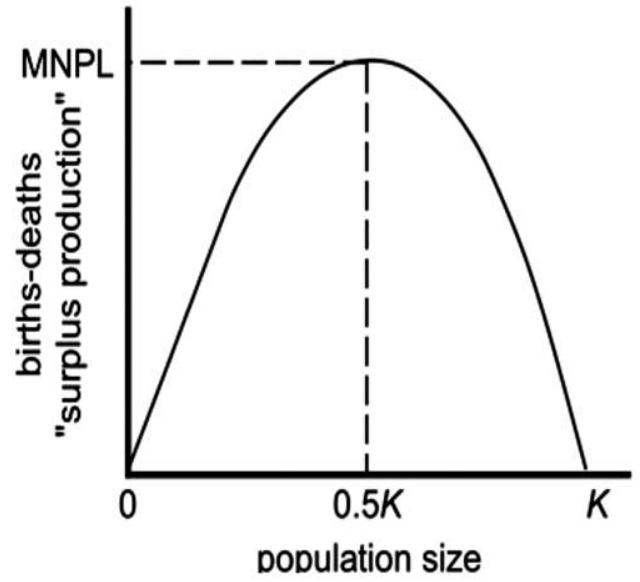

(c)

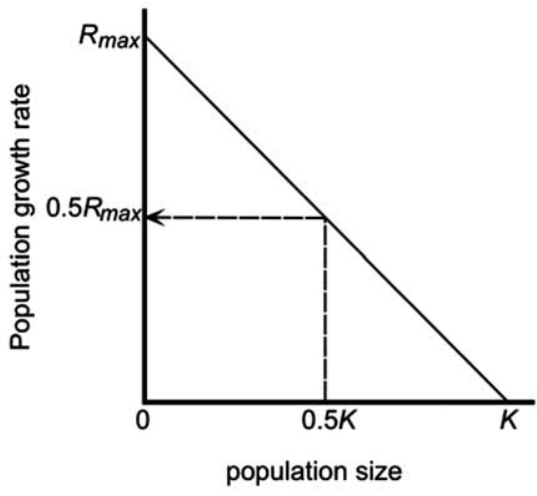

Fig. (1). Plots showing the relationships among components used in the PBR equation.

the goal is to ensure populations stay at or above MNPL (i.e. above $0.5 \mathrm{~K}$ ) the population growth rate used in the PBR calculation is $0.5 \mathrm{R}_{\max }$.

Default values for $R_{\max }(0.04$ for cetaceans and 0.12 for pinnipeds) can be used if no estimates of population growth rates are available for the species in question. When data on productivity are available it is recommended that they be used [6]. Estimates of survival and reproductive rates for Hector's dolphin are available from a long-term research programme that began in 1984 and is ongoing. $R_{\max }$ has been estimated at 0.018 based on marine mammal survival rate curves and the most optimistic reproductive parameters (age at first reproduction and calving interval) estimated in the field [11]. $\mathrm{R}_{\max }$ values of around 0.04 would be achievable only with survival rate schedules from human studies (excluding predation). Here we calculate PBRs using the $\mathrm{R}_{\max }$ estimate for Hector's dolphin (0.018). PBRs based on the much higher default value for cetaceans in general (0.04) are also included for comparison.

Bias trials (simulations that included plausible levels of bias in the available information) indicated that $F_{r}$ needs to be $\leq 0.5$ to meet performance criteria (1) and (2) above. Taylor and Wade [12] showed that using $\mathrm{N}$ (rather than $\mathrm{N}_{\min }$ ) and $F_{r} 1.0$ resulted in many of the simulated populations being depleted below $0.5 \mathrm{~K}$. They also carried out robustness trials, similar to those used by the Scientific Committee of the International Whaling Commission in testing its Revised Management Procedure [13]. Two plausible flaws in the data or assumptions were explored, based on biases (e.g. in abundance and mortality estimates) similar to those observed in the management of marine mammal bycatch [12]. Additional simulation trials were carried out by Wade [6]. For endangered species an $F_{r}$ of 0.1 is recommended $[6,14]$. For example, North Atlantic right whale with a population of about 300 individuals, would have a PBR of $<1$ individual per year. With a PBR this low, managers decided that the PBR was essentially zero and set the goal of reducing fisheries mortality to levels as close to zero as practicable. In the discussion, below, we consider examples of similar decisions and provide a more detailed discussion of the design features of the PBR method, including setting $\mathrm{F}_{\mathrm{r}}$.

\section{RESULTS}

PBRs for individual areas are presented in Table 1, with the area boundaries shown in Fig. (2).

It is obviously important to ensure that the areas used in the PBR calculations are of an appropriate size. This means that the scale over which bycatch occurs must match the area used for abundance calculation. If these areas are too large, the abundance of the impacted population will be overestimated, resulting in population depletion [14-17]. For example, if a PBR were calculated for the entire east coast of the South Island of New Zealand but gillnet fishing were carried out only in part of this area, then fishing to the limit of the PBR would result in depletion of the population in the area where the fishery is operating. Scientists involved in the design of the PBR method recommend starting with management areas based on the smallest groupings which are biologically reasonable and practical from a management perspective [15-17]. Many sources of data can be used to 
Table 1. Estimated Population Size $(\mathrm{N}), 20^{\text {th }}$ Percentile of Population Size $\left(\mathrm{N}_{\min }\right)$ and PBRs Calculated Using the $\mathbf{R}_{\max }$ Default for Cetaceans $(0.04)$ and $\mathbf{R}_{\max }$ Estimate for Hector's Dolphin $(\mathbf{0 . 0 1 8}) . \mathrm{F}_{\mathrm{r}}=\mathbf{0 . 1}$ Given the Endangered Status of the Species

\begin{tabular}{|c|c|c|c|c|}
\hline & N & Nmin & PBR & PBR \\
\hline Rmax & & & $\mathbf{0 . 0 4}$ & $\mathbf{0 . 0 1 8}$ \\
\hline Area & & & & \\
\hline \hline A & 111 & 78 & 0.16 & 0.07 \\
\hline B & 20 & 10 & 0.02 & 0.01 \\
\hline C & 162 & 105 & 0.21 & 0.09 \\
\hline D & 102 & 65 & 0.13 & 0.06 \\
\hline E & 300 & 223 & 0.45 & 0.20 \\
\hline F & 310 & 245 & 0.49 & 0.22 \\
\hline G & 89 & 68 & 0.14 & 0.06 \\
\hline H & 74 & 38 & 0.08 & 0.03 \\
\hline I & 400 & 312 & 0.62 & 0.28 \\
\hline J & 1195 & 728 & 1.46 & 0.66 \\
\hline K & 695 & 569 & 1.14 & 0.51 \\
\hline L & 1343 & 1024 & 2.05 & 0.92 \\
\hline M & 1481 & 1192 & 2.38 & 1.07 \\
\hline N & 86 & 49 & 0.10 & 0.04 \\
\hline O & 84 & 40 & 0.08 & 0.04 \\
\hline \hline
\end{tabular}

elucidate population structure, including distribution and movements, morphological differences, genetics, contaminants and natural isotope loads and parasite differences [16]. In the absence of biological data that allows populations to be subdivided into local subpopulations, a management area should be defined simply as the area from which marine mammals are taken (i.e., the area in which the fishery is operating) [16]. If human-caused mortality occurs in only a portion of a population's geographic range, care should be taken to avoid lumping areas, leading to the depletion and potentially extirpation of some populations. Clearly, situations where human impact is likely to hit certain segments of the population much harder than others should be avoided. Splitting is preferred in situations where incorrectly lumping could lead to the depletion of a population [16] with small management areas only "lumped" when there is compelling evidence to do so (e.g. data on distribution, movements, genetics, pollutant loads, etc.). Barlow et al. [16] have shown that populations can be depleted under the PBR scheme if subpopulations with low mixing $(<2 \%$ per year) are mistakenly managed as a single unit. When mixing rates are uncertain, management should therefore include assessment of whether the population differentiation technique has sufficient power to detect the population structure relevant to the PBR management scheme. Large, panmictic populations are rare. To define a small area as a management unit does not require statistical evidence of population differentiation. In general, in the absence of data, this is likely the most effective conservation strategy.

We were asked by the Department of Conservation to calculate $\mathrm{N}_{\min }$ and PBRs for Hector's dolphins in eight areas on the west coast of the South Island [18] and these are the areas shown in Fig. (2). We have extended this work to include all areas where Hector's dolphins are found. The areas for which PBRs were calculated followed the advice above in being sufficiently small that it is unlikely that more than one discrete population or more than one discrete fishery is present in any one of the areas. The boundaries of the areas were based on genetic differences, gaps in distribution and/or obvious changes in population density. The only exception is the North Island population which is dealt with as a whole, despite the possibility that it may comprise more than one discrete population. It did not seem worthwhile to further subdivide the North Island population, given that abundance is very low $(111, \mathrm{CV}$ 0.44) [10]. This and the existence of a protected area mean that the PBR for the North Island is essentially zero [e.g. 4]. Nevertheless, the North Island has been included in Table $\mathbf{1}$ for completeness and for comparison with PBRs for other Hector's dolphin populations around the South Island. Area E includes the Banks Peninsula Marine Mammal Sanctuary. The individuals inside this protected area have been excluded from the PBR calculation. Including the individuals in the sanctuary increases the PBR for the Area E to 0.84 or 1.87 depending on whether the $R_{\max }$ for Hector's dolphin or the default $R_{\max }$ is used.

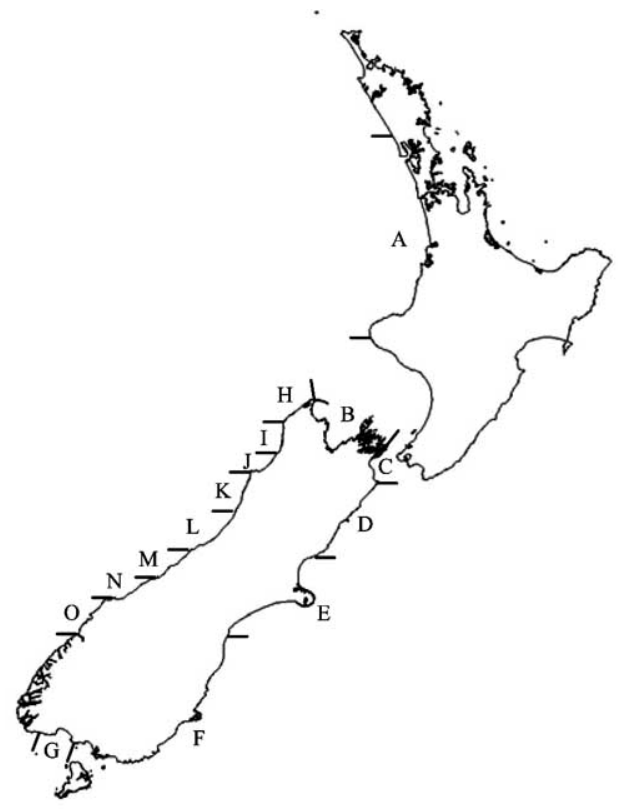

Fig. (2). Area boundaries used in Table 1.

Actual catches are much higher than these PBRs. Area E has had the best observer coverage. Based on dolphin catches observed by independent observers on fishing boats it has been estimated that an average of 28 Hector's dolphins per year were caught in this area during 2000-2006 [20]. This is on the order of 60-140 times the PBR for this area. 
Even if dolphins inside the Banks Peninsula Marine Mammal Sanctuary are included in the PBR calculation, bycatch is still 15-33 times higher than the PBR. This ratio is similar for the country as a whole, with current total bycatch around NZ estimated at 110-150 Hector's dolphins per year [20], 12-35 times higher than the total of the PBRs in Table 1. (4.3 or 9.5 depending on which $R_{\max }$ is used). Past dolphin catches were even higher. For example, in the mid 1980s, catches in Area E alone were estimated via interviews with fishers at on average at least 57 per year [19] and based on observer data at around 100 individuals per year [20].

\section{DISCUSSION}

PBRs for Hector's dolphins are very low at less than 1 individual per year for most areas. Current estimated bycatch is on the order of 10-35 times higher than these PBRs. This is consistent with several Population Viability Analyses indicating that under current management populations are declining rapidly [e.g. 5, 20].

The PBR method helps to determine levels of humancaused mortality that are likely to lead to population decline. Most people would agree that an activity could be considered acceptable if it only rarely causes marine mammal deaths (e.g. one animal in $20 \mathrm{yr}$ ) [6]. For example, vessel collisions with dolphins and whales are a relatively rare occurrence in areas with light shipping traffic. Hector's dolphins are from time to time struck by vessels and injured or killed [21]. Currently, these events appear to be rare and with existing shipping levels are probably sustainable for the species. On the other hand, speedboat races or fast-ferries could be a serious risk in areas where Hector's dolphins are found. The PBR method helps to determine at what point a human impact is likely to lead to population depletion [6].

By the mid 1990s management methods relying on direct detection of population declines or population status relative to $\mathrm{K}$ or MNPL had proven inadequate and the PBR method had been developed to replace them [e.g. 6, 12, 36]. The variance typically associated with population estimates means that statistical power to detect declines is low, and in many cases even a decline of $50 \%$ would not be detectable statistically. Therefore, the time required to detect population declines (e.g. by aerial or boat surveys) is so long that management action based on such detection would not be initiated until populations have been seriously depleted. Likewise, estimates of population size relative to $\mathrm{K}$ or MNPL (e.g. by back-calculation) $[5,22]$ tend to be relatively uncertain or at least open to challenge [e.g. 5, 23, 24]. For these reasons, NMFS decided to develop a management method based not on detecting population depletion but on calculating a mortality level likely to lead to depletion. This new approach is part of a broader trend in developing management procedures that use data that can be readily and reliably obtained using best-practice research methods. For example, the International Whaling Commission has also re-focussed its management procedure to be based on the most reliable scientific data available.

The PBR method has two major strengths: (1) The method is simple to apply and easily explained to a wide range of stakeholders and (2) can be applied with a range of available data. For example, if extensive data are available on population size, level of depletion compared to $\mathrm{K}$ and
MNPL, population growth rates, levels of human impact, etc. these can all be used in setting $\mathrm{N}_{\min }, \mathrm{R}_{\max }$ and $\mathrm{F}_{\mathrm{r}}$ and in determining whether current impacts exceed the PBR. Even if very little information is available for the species, it is possible to use the PBR method to estimate a level of human impact that is unlikely to cause population decline. For example, if all that is available is a rough estimate of population size, this can be used to determine $\mathrm{N}_{\min }$. $\mathrm{R}_{\max }$ can be set at the default value and $F_{r}$ can be set conservatively. An estimate of population size is a basic requirement for any conservation management. However, if all that is available is an estimate of the number of dolphins killed each year it is still possible to use the PBR method to estimate the population size required to sustain this level of impact. For example, the estimated 28 Hector's dolphins per year caught in the Area E during 2000-2006 [20] can be used in the PBR equation to solve for $\mathrm{N}_{\min }$ (using the default $\mathrm{R}_{\max }$ for cetaceans of 0.04 , and an $\mathrm{F}_{\mathrm{r}}$ of 0.1 given the species' Endangered status). This would indicate that $\mathrm{N}_{\text {min }}$ would need to be at least 14,000 individuals. Even if a robust population estimate for Area E were not available it would be obvious that 14,000 far exceeds the number of dolphins there. In fact, the population would need to be considerably larger than 14,000 individuals for several reasons, including: (a) Dolphin mortalities also occur in the trawl fishery and recreational gillnet fishery, neither of which have quantitative estimates of bycatch (it has not been possible to include these sources of mortality in risk analyses to date), (b) Other human impacts include boat strikes, pollution, aquaculture, marine mining etc. (c) Part of the local population is legally protected by the Banks Peninsula Marine Mammal Sanctuary, therefore the $\mathrm{N}_{\text {min }}$ estimate of 14,000 should apply to the population north, south and offshore of that protected area, (d) 14,000 is an estimate of the $\mathrm{N}_{\min }\left(20^{\text {th }}\right.$ percentile) required to ensure that the $28 \mathrm{hu}$ man-caused deaths do not cause population depletion. Therefore the point estimate for population size $(\mathrm{N})$ would need to be considerably higher. [Assuming a CV of 0.3 (an excellent achievement for a dolphin survey), the population estimate would need to be 17,920].

The PBR method explicitly takes into account uncertainty caused by imprecision and potential biases in the available information as well as any information gaps. With perfect knowledge, the product of $\mathrm{N}$ and $0.5 \mathrm{R}_{\max }$ would exactly maintain populations at $0.5 \mathrm{~K}$. Small populations would increase and large populations would decrease in size until they reached $0.5 \mathrm{~K}$. Using $\mathrm{N}_{\text {min }}$ instead of $\mathrm{N}$ accounts for imprecision in the abundance estimate, as quantified in the Coefficient of Variation (CV) or similar measure of variability for $\mathrm{N}$.

Taylor and Wade [12] used the analogy of target shooting. Instead of aiming for the centre of a bullseye the goal is to shoot above a horizontal line, symbolising the goal of maintaining populations above MNPL. The goal is to ensure that $95 \%$ of your shots hit above the line and you have a choice of two guns. One is an old-style musket and the other a sniper's rifle. The rifle shoots with great precision and is equivalent to a very precise abundance estimate (with a very low CV). Even an expert at target shooting will be much less precise with the musket. Repeated shots with the musket produce a more scattered pattern of bullet holes than the rifle. To ensure a high proportion of the shots hit above the line, one would need to deliberately aim the musket higher 
than the rifle. Using Nmin in the PBR equation is analagous to raising the aiming point to adjust for poorer precision. How high above the line one needs to aim was determined by simulation trials to simulate management of marine mammal bycatch, resulting in $\mathrm{N}_{\text {min }}$ being set at the $20^{\text {th }}$ percentile of the abundance estimate $[6,12]$.

The PBR method also takes account of bias and other forms of uncertainty which can't be readily estimated. $F_{r}$ takes account of potential biases in input data, as well as uncertainty caused by a lack of data on important factors such as population boundaries. $F_{r}$ also ensures that population recovery occurs at an acceptable rate. For very small or Endangered populations $F_{r}$ is usually set at 0.1 . The goal for these populations is recovery towards $0.5 \mathrm{~K}$ as quickly as possible. Reducing the time spent at very small population size is important because such small populations are highly vulnerable to environmental and demographic stochasticity, and inbreeding [25]. Put simply, small population size is a risk in itself, and reducing the amount of time spent at very small population sizes significantly improves the probability of recovery. For example, in the United States, most large whales were listed as Endangered because they had been reduced to low population levels by commercial whaling. Therefore, an $\mathrm{F}_{\mathrm{r}}$ of 0.1 was used, to help ensure that there would be no more than a $10 \%$ increase in the time to recovery [16]. For some populations, even an $F_{r}$ of 0.1 is considered insufficiently cautious, and the PBR has been set to zero for several populations. For example, North Atlantic right whales number only about 300 individuals and are subject to several human impacts, including ship strikes and entanglement in fishing gear. It has been estimated that preventing the deaths of two or three adult females per year would substantially reduce extinction risk [26]. Taking these factors into account, managers have decided that setting a PBR would be insufficiently precautionary and fisheries bycatch should be reduced as close to zero as is practicable, essentially setting the PBR to zero [27]. Following similar logic, PBRs for Hector's dolphin populations on the North Island west coast and South Island south coast have been set to zero [4].

These decisions reflect the fact that managing very small populations involves additional considerations and the PBR method on its own is not sufficiently cautious [6, 27, 28]. The model used in testing the PBR method does not include an Allee Effect (reduced population growth at small population sizes) which can dramatically increase probability of extinction and is likely to delay recovery [6]. For very small marine mammal populations, any impacts may be biologically significant. For such populations, the effect of human impacts needs to be evaluated in the context of how much it might increase the risk of extinction for the population [6, 28-30] taking into account factors such as environmental stochasticity, demographic stochasticity and the Allee Effect [31].

Methods developed to calculate quotas for whaling [e.g. 32-36] and limits for marine mammal bycatch in fisheries [6] aim to maintain relatively large populations at or above the level at which they are most productive. However, these models do not take into account the increased threat of extinction that could be caused by human impacts nor do they consider the population dynamics of very small populations.
Wade and Slooten [28] present a method for quantifying the increased risk of extinction caused by deliberate or unintentional removals of individuals from small populations and point the way towards a revised PBR method for small and endangered populations. Bearing in mind these caveats, the PBR method provides a useful indication of the maximum acceptable impact and the minimum level of protection required to avoid population depletion.

The results of this PBR analysis are certainly consistent with Population Viability Analyses [5, 37-39] and fisheries models [20] developed for Hector's dolphins. All of these analyses clearly indicate that a much higher level of protection is required in order to halt population declines. With PBRs $<1$ for most populations and current levels of bycatch on the order of 10-35 times higher than the PBRs, it is clear that current management is not effective.

The recently released Threat Management Plan (TMP) presents a range of management options to provide better protection for Hector's dolphins [4]. Two independent risk analyses have compared the effectiveness of these management options [5, 20]. Both analyses clearly indicate that current management would result in continued population decline (to $<6,000$ individuals within 50 years). Option 1 in the TMP is very similar to current management and is therefore unlikely to decrease significantly the number of dolphins caught. Option 2 involves closing additional inshore areas to gillnetting (out to 2 or 4 nautical miles offshore, depending on the area) and trawling (out to 2 nautical miles, with exceptions for some target species), either year-round or seasonally. This mix of protection measures (some area closures, some seasonal, some areas left unprotected, including regulations and voluntary measures) is difficult to evaluate quantitatively. Also, compliance under this option is likely to be poor and difficult to quantify. It is clear that Option 1 and 2 are very unlikely to reduce fisheries mortality (let alone total human impact) to below PBR levels. On the other hand, Option 3 would clearly be effective and has the potential to result in population recovery to an estimated 14,799-15,411 individuals within 50 years $[5,20]$. Option 3 includes restrictions on gillnetting in waters less than $100 \mathrm{~m}$ deep (out to 6 , 12 or 18 nautical miles offshore depending on the area) and restrictions on trawling (within 2 or 4 nautical miles, depending on the area).

Observer programmes would be required to monitor whether bycatch is reduced below PBR levels under any of the options, in particular Options 1 and 2 which would allow continued gillnet and trawl fisheries for large parts of the current range of the species. None of the options in the draft TMP include complete protection from fisheries mortality, which would likely be required to ensure total human impacts on the species (which include pollution, marine mining and boat strikes) are reduced to below PBR levels. To put the estimated rate of recovery for Option 3 into perspective, the PBR method aims to ensure recovery to at least $0.5 \mathrm{~K}$ within 100 yrs and the New Zealand Marine Mammal Protection Act aims to ensure that threatened species become nonthreatened within 20 yrs. In summary, Option 3 would be the minimum required to meet national and international goals for marine mammal conservation and to reduce human impacts on the species to below the PBR. 


\section{CONCLUSIONS}

PBRs are presented as a guide to how much protection is needed for the species, rather than as proposed catch limits. Given the very low PBRs $(<1$ individual per year for most areas) and difficulties in monitoring and policing bycatch and other threats to the species, it would not be practical to use PBRs as 'real time' triggers for closing the fishery when the PBR is reached [40].

The PBRs for Hector's dolphins presented here are a maximum level of total human impact which, if exceeded, would likely cause further population depletion. Fisheries mortality needs to be kept well below these levels, given that there are other human impacts on the species. Even Option 3, the most effective management option in the TMP, may not achieve this. A precautionary approach is essential for the following reasons. As explained above, the PBR method does not take into account the specific requirements of very small, endangered populations. With PBRs $<1$ for most areas where Hector's dolphins are found the management objective should be to reduce fishing impacts to as close to zero as practicable. This could be achieved by changing to more selective, sustainable fishing methods. This would have benefits not only for Hector's dolphin conservation but also for other dolphin species and seabirds caught in these fisheries, and in the long term for the fishing industry itself. Using more selective, sustainable methods will ensure the long term viability of the fishery itself.

\section{ACKNOWLEDGMENTS}

We are very grateful for discussions with several scientists from the US National Marine Fisheries Service who were closely involved with the development of the PBR method. In particular, Jay Barlow, Barbara Taylor, Paul Wade and Doug deMaster. We also thank them for having developed this elegantly simple, yet robust method.

\section{REFERENCES}

[1] IUCN. Red List of Threatened Species 2006; www.iucnredlist.org.

[2] Baker AN, Smith ANH, Pichler FB. Geographical variation in Hector's dolphin: Recognition of new subspecies of Cephalorhynchus hectori. J Roy Soc New Zeal 2002; 32: 713-27.

[3] Read AJ, Drinker P, Northridge S. Bycatch of marine mammals in the US and global fisheries. Conserv Biol 2006; 20: 163-9.

[4] DOC \& Mfish. Hector's and Maui's dolphin threat management plan. Draft for public consultation. Published by Department of Conservation and Ministry of Fisheries. August 2007; Available from: www.fish.govt.nz

[5] Slooten E. Conservation management in the face of uncertainty: Effectiveness of four options for managing Hector's dolphin bycatch. Endang Species Res 2007; 3: 169-79.

[6] Wade PR. Calculating thresholds to the human-caused mortality of cetaceans and pinnipeds. Mar Mamm Sci 1998; 14: 1-37.

[7] Taylor BL, DeMaster DP. Implications of non-linear density dependence. Mar Mamm Sci 1993; 9: 360-371.

[8] Dawson SM, Slooten E, DuFresne S, Wade P, Clement D. Smallboat surveys for coastal dolphins: Line-transect surveys for Hector's dolphins (Cephalorhynchus hectori). Fish Bull 2004; 201: 441-51.

[9] Slooten E, Dawson SM, Rayment WJ. Aerial surveys for coastal dolphins: Abundance of Hector's dolphins off the South Island west coast, New Zealand. Mar Mamm Sci 2004; 20: 477-490.

[10] Slooten E, Dawson SM, Rayment WJ, Childerhouse SJ. A new abundance estimate for Maui's dolphin: What does it mean for managing this critically endangered species? Biol Conserv 2006; 128: 576-81.

[11] Slooten E, Lad F. Population biology and conservation of Hector's dolphin. Can J Zool 1991; 69: 1701-7.
Taylor BL, Wade PR. "Best" abundance estimates and best management: Why they are not the same. In: Ferson S, Burgman M, Eds. Quantitative Methods for Conservation Biology. NY, Springer 2000; 96-108.

[13] Donovan GP. The comprehensive assessment of whale stocks: the early years. Rep Int Whal Commn 1989; (Spec Issue 11).

[14] Wade PR, Angliss RP. Guidelines for assessing marine mammal stocks: Report of GAMMS Workshop, 1996, Seattle, Washington. NOAA Technical Memorandum 1997; NMFS-OPR-12.

[15] Taylor BL. Defining "population" to meet management objectives for marine mammals. In: Dizon AE, Chivers SJ, Perrin WF, Eds. Molecular Genetics of Marine Mammals. Lawrence, Kansas. Soc for Mar Mamm 1997; Spec Publ 3: 347-364.

[16] Barlow J, Swartz SL, Eagle TC, Wade PR. US Marine Mammal Stock Assessments: Guidelines for Preparation, Background, and a summary of the 1995 assessments. NOAA Technical Memorandum 1995; NMFS-OPR-95-6.

[17] Taylor BL. Identifying units to conserve. In: Reynolds JE III, Perrin WF, Reeves RR, Montgomery S, Ragen, TJ, Eds. Marine mammal research: Conservation beyond crisis. Baltimore MD, John Hopkins Univ Press, 2005; 149-164.

[18] Dawson SM. Fine-scale abundance estimates from the 2000/2001 aerial survey of Hector's dolphins on the South Island west coast. DOC Science Internal Series. Available from: Department of Conservation, Wellington 2001;21: 9 .

[19] Dawson SM. Incidental catch of Hector's dolphins in inshore gillnets. Marine Mammal Science 1991; 7(3): 283-295.

[20] Davies NM, Bian R, Starr P, Lallemand P, Gilbert D, McKenzie J. Risk analysis for Hector's dolphin and Maui's dolphin subpopulations to commercial set net fishing using a temporal-spatial agestructured model. Ministry of Fisheries, Wellington, New Zealand 2008; Available from: www.fish.govt.nz/en-nz/Consultations/ Hector+new/ default.htm

[21] Stone GS, Yoshinaga A. Hector's dolphin (Cephalorhynchus hectori) calf mortalities may indicate new risks from boat traffic and habituation. Pac Cons Biol 2000; 6: 162-70.

[22] Smith T. Changes in three dolphin (Stenella spp.) populations in the eastern tropical Pacific. Fish Bull 1983; 81: 1-13.

[23] Middleton DA, Starr PJ, Gilbert DJ. Modelling the impact of fisheries bycatch on Hector's dolphin. Endang Species Res 2007; 3: 331-4.

[24] Slooten E. Criticism is unfounded: Reply to Middleton et al. Endang Species Res 2007; 3: 335-339.

[25] Lande R. 1999 Extinction risks from anthropogenic, ecological and genetic factors. In: Landweber LF, Dobson AP, Eds. Genetics and the extinction of species. Princeton University Press 1999; 1-22.

[26] Fujiwara M, Casswell H. Demography of the endangered North Atlantic right whale. Nature 2001; 414: 537-41.

[27] Waring GT, Quintal JM, Fairfield CP, Eds. U.S. Atlantic and Gulf of Mexico Marine Mammal Stock Assessments - 2002. US Department of Commerce, NOAA Technical Memorandum 2002; NMFS-NE-169: 328.

[28] Wade PR, Slooten E. Extinction risk from human impacts on small populations of marine mammals. Submitted to Mar Mam Sci 2008.

[29] Gilpin ME, Soule ME. Minimum viable populations: processes of species extinction. In: Soule ME, Ed. Conservation biology: the science of scarcity and diversity. Sunderland, MA, Sinauer Associates 1986; 19-34

[30] Beissinger SR, Westphal MI. On the use of demographic models of population viability in endangered species management. J Wild Man 1998; 62: 821-41.

[31] Petersen, CW, Levitan DR. 2001. The Allee effect: A barrier to recovery by exploited species. In: Reynolds JD, Mace GM, Redford $\mathrm{KH}$, Robinson JG, Eds. Conservation of exploited species. Cambridge, MA, Cambridge University Press 2001; 281-300.

[32] Kirkwood GP. Background to the development of revised management procedures. Rep Int Whal Commn 1992; 42: 236-43.

[33] Cooke JG. The management of whaling. Aq Mamm 1994; 20: 129135.

[34] Cooke JG. The International Whaling Commission's revised management procedure as an example of a new approach to fishery management. In: Blix AS, Walloe L, Woltang O, Eds. Whales, seals, fish and man. Amsterdam, Elsevier Science 1995; 647-657

[35] Slooten E. Risk analysis at the International Whaling Commission. In: Fletcher DJ, Kavalieris L, Manly BFJ, Eds. Statistics in ecology and environmental monitoring II: Risk assessment and decision 
making in biology. Dunedin, New Zealand, Otago University Press 1998; 173-180.

[36] Taylor BL, Wade PR, DeMaster DP, Barlow, J. Incorporating uncertainty into management models for marine mammals. Conserv Biol 2000; 14: 1243-52.

[37] Burkhart SM, Slooten E. Population viability analysis for Hector's dolphin (Cephalorhynchus hectori): A stochastic population model for local populations. NZ J Mar Freshwat Res 2003; 37: 553-66.

[38] Martien KK, Taylor BL, Slooten E, Dawson S. A sensitivity analysis to guide research and management for Hector's dolphin. Biol Conserv 1999; 90: 183-91.

[39] Slooten E, Fletcher D, Taylor BL. Accounting for uncertainty in risk assessment: Case study of Hector's dolphin mortality due to gillnet entanglement. Conserv Biol 2000; 14: 1264-1270.

[40] Dawson SM, Slooten E. Management of gillnet bycatch of cetaceans in New Zealand. J Cet Res Mgt 2005; 7: 59-64.

Received: April 02, 2008 Revised: September 17,2008 Accepted: September 19,2008

(C) Slooten and Dawson; Licensee Bentham Open.

This is an open access article licensed under the terms of the Creative Commons Attribution Non-Commercial License (http://creativecommons.org/licenses/by-nc/3.0/) which permits unrestricted, non-commercial use, distribution and reproduction in any medium, provided the work is properly cited. 